\title{
Ventilator-associated pneumonia after elective cardiac surgery caused by Pneumocystis jirovecii
}

\begin{abstract}
Eduardo Tobar ${ }^{\mathrm{a}, \mathrm{b}}$, Francisco Silva ${ }^{\mathrm{b}}$, Anibal Zamorano ${ }^{\mathrm{c}}$, Marcela Cifuentes ${ }^{\mathrm{b}}$, Robert F. Miller ${ }^{\mathrm{d}, \mathrm{e}}$ and Sergio L Vargas ${ }^{\mathrm{f}}$

${ }^{a}$ Unidad de Pacientes Críticos, Departamento de Medicina, Hospital Clínico Universidad de Chile, Avenida Santos Dumont 999, Independencia 8380456, Santiago, Chile; ${ }^{b}$ Unidad de Prevención y Control de Infecciones Asociadas a la Atención en Salud (UPC-IAAS), Hospital Clínico Universidad de Chile, Avenida Santos Dumont 999, Independencia 8380456, Santiago, Chile; ' Centro Cardiovascular, Hospital Clínico Universidad de Chile, Avenida Santos Dumont 999, Independencia 8380456, Santiago, Chile; ${ }^{d}$ Research Department of Infection and Population Health, Institute of Epidemiology and Healthcare, University College London, Mortimer Market, London, WC1E 6JB, UK; ${ }^{e}$ Clinical Research Department, London School of Hygiene and Tropical Medicine, Kepple Street, London, WC1E 7HT, UK; 'Programa de Microbiología y Micología, Instituto de Ciencias Biomédicas, Facultad de Medicina, Universidad de Chile, Independencia 1027, Independencia 8380453, Santiago, Chile
\end{abstract}

Corresponding address: Professor Robert Miller, Research Department of Infection and Population Health, Institute of Epidemiology and Healthcare, University College London, Mortimer Market Centre, off Capper Street, London, WC1E 6JB, UK.

Email: robert.mi11er@uc1.ac.uk

Date accepted for publication 16 June 2014

\section{Abstract}

Ventilator-associated pneumonia is a severe complication among patients undergoing cardiac surgery. Although hospital-acquired bacterial pathogens, often multidrug resistant, are the most frequent cause, non-bacterial atypical and opportunistic agents traditionally associated with immunocompromise are increasingly recognized. We describe ventilator-associated pneumonia due to Pneumocystis jirovecii in the absence of traditional risk factors for Pneumocystis pneumonia in a patient after cardiac surgery.

\section{Keywords}

Ventilator-associated pneumonia; Pneumocystis jirovecii; cardiac surgery; intensive care.

\section{Introduction}

Ventilator-associated pneumonia (VAP) is an important condition, given its morbidity, mortality and associated health care costs ${ }^{[1]}$. Common causes of VAP include multidrug-resistant bacteria such as Pseudomonas aeruginosa, Acinetobacter baumannii, Stenotrophomonas maltophilia and methicillin-resistant Staphylococcus aureus ${ }^{[2]}$, however atypical and opportunistic pathogens,

This paper is available online at http://www.grandrounds-e-med.com. In the event of a change in the URL address, please use the DOI provided to locate the paper. 
including Chlamydia pneumoniae and Mycoplasma pneumoniae, Candida albicans and other fungi, are increasingly recognized in patients who have undergone cardiothoracic surgery ${ }^{[3,4]}$. We describe a patient with VAP caused by another opportunistic organism, Pneumocystis jirovecii, in the absence of traditional risk factors for Pneumocystis pneumonia (PCP).

\section{Case report}

A 64-year-old woman with rheumatic mitral valve disease presented with progressive impairment of functional capacity resulting in heart failure (New York Heart Association Functional Class III). Her past medical history was unremarkable and the patient was not taking corticosteroids or other immunosuppressive therapy. On examination, the patient had a normal nutritional status (body mass index $=19.5 \mathrm{~kg} / \mathrm{m}^{2}$ ), there was no lymphadenopathy or organomegaly, and no stigmata of Cushing syndrome were evident. Echocardiography showed moderate to severe mitral regurgitation, mild mitral stenosis, a left ventricular ejection fraction of $40 \%$, and severe tricuspid regurgitation. Coronary angiography and a high-resolution chest computed tomography (CT) scan were normal. A human immunodeficiency virus (HIV) test (ELISA combined HIV-1 and HIV-2 antibody plus HIV-1 p24 antigen) was negative, and blood glucose and serum albumin levels, neutrophil and total lymphocyte counts, and biochemical tests of renal, liver, and bone function were normal.

The patient underwent mitral valve replacement (Carpentier Edwards PERIMOUNT; Edwards Lifesciences, Irvine, CA) and tricuspid valve repair surgery. During the immediate $(2-8 \mathrm{~h})$ postoperative period she developed cardiovascular instability requiring vasopressor support and mechanical ventilation. Echocardiography revealed moderate biventricular systolic dysfunction without an abnormal mitral gradient. Vasopressor drugs were withdrawn, loop diuretics were started, and weaning from mechanical ventilation was achieved by $24 \mathrm{~h}$ postoperatively.

Despite a negative fluid balance and intermittent non-invasive ventilatory bilevel positive airway pressure, the patient deteriorated, with increased work of breathing, hypoxemia $\left(\mathrm{PaO}_{2}: \mathrm{Fio}_{2}\right.$ ratio $<150$ ), and radiographic evidence of new infiltrates, and was re-intubated on the fifth postoperative day. The acute lung injury was ascribed to VAP; inflammatory markers showed white blood cells $(\mathrm{WBC})=18,200$ cells $/ \mu \mathrm{l}$, C-reactive protein $=300 \mathrm{mg} / \mathrm{l}($ normal $<5 \mathrm{mg} / \mathrm{l})$ and procalcitonin $=5.9 \mathrm{ng} / \mathrm{ml}$ (normal $<0.15 \mathrm{ng} / \mathrm{ml}$ ). After collecting urine, peripheral and central line blood samples for culture, and an endotracheal aspirate for quantitative cultures, empiric antibiotic therapy was initiated with piperacillin/tazobactam with vancomycin.

A CT scan of the chest, done $6 \mathrm{~h}$ before re-intubation showed diffuse bilateral alveolar infiltrates and ground-glass opacities with sparing of the basal segments of the lower left lobe. The patient deteriorated, developing cardiovascular failure requiring vasopressor and inotropic support. Microbiological studies were negative, and so vancomycin was stopped and piperacillin/ tazobactam was continued. The patient stabilized hemodynamically, and inflammatory markers improved $(\mathrm{WBC}=13,400$ cells $/ \mu \mathrm{l}$, C-reactive protein $=74 \mathrm{mg} / \mathrm{l}$, and procalcitonin $=0.88 \mathrm{ng} / \mathrm{ml}$ ); serum amylase and bilirubin levels were normal.

By the eighth day of mechanical ventilation, the respiratory failure had worsened with development of multiple organ dysfunction (acute renal failure and thrombocytopenia; serum bilirubin and amylase levels remained normal). In addition, inflammatory markers had deteriorated together with the reappearance of cardiovascular instability. On day 13 of mechanical ventilation, a thoracic CT scan showed diffuse bilateral alveolar infiltrates with dilatation and distortion of bronchial structures. New alveolar infiltrates were seen in the left lung (Fig. 1) and bronchoscopic alveolar lavage (BAL) via the endotracheal tube was done. Postbronchoscopy VAP treatment was escalated, with re-initiation of vancomycin and empiric administration of imipenem, fluconazole and amikacin. Analysis of BAL fluid for detection of bacterial pathogens (by microscopy and culture) was negative, as were molecular detection tests for influenza A and B and respiratory syncytial virus. BAL fluid was negative for hemosiderinladen macrophages, excluding occult alveolar haemorrhage as a cause.

Despite empiric antibiotics, and inotropic, vasopressor and ventilator support, the patient deteriorated and died on the 20th postoperative day. The family refused permission for necropsy. After the patient's death, analysis of stored BAL fluid showed the presence of $P$. jirovecii in single forms or typical clusters (one every ten fields at $\times 20$ magnification), demonstrated by GrocottGomori methenamine silver stain (Fig. 2a), and by detection of Pneumocystis-specific DNA using a single round polymerase chain reaction (PCR) using the oligonucleotide primers, pAZ102E and 


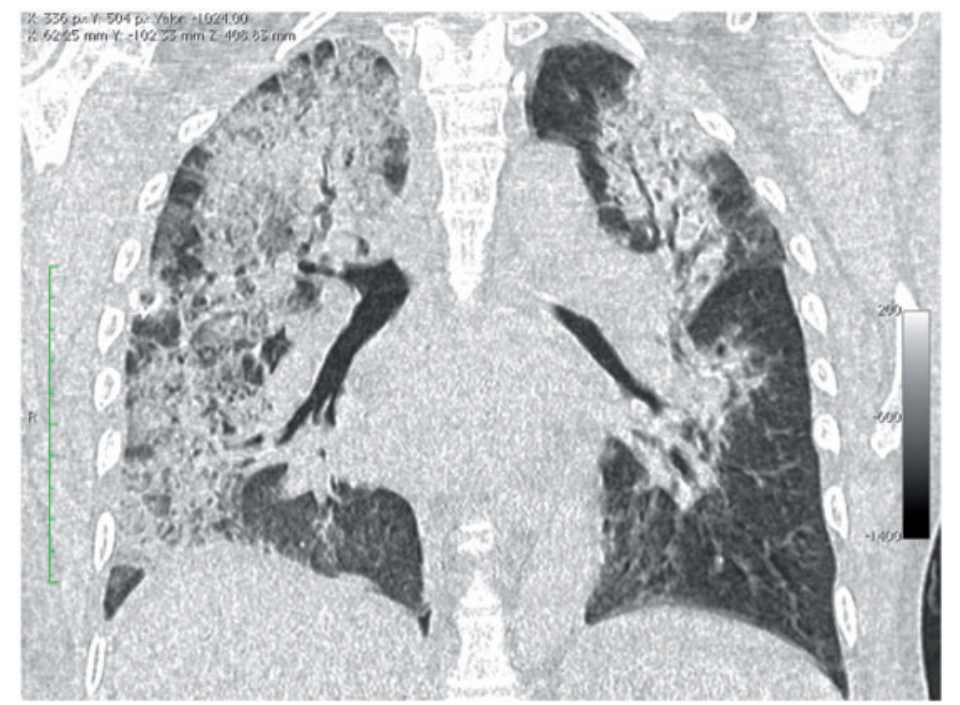

Fig. 1. CT thorax performed after 13 days of mechanical ventilation, showing diffuse bilateral alveolar infiltrates with areas of ground-glass opacity, and dilatation and distortion of bronchial structures.

(a)

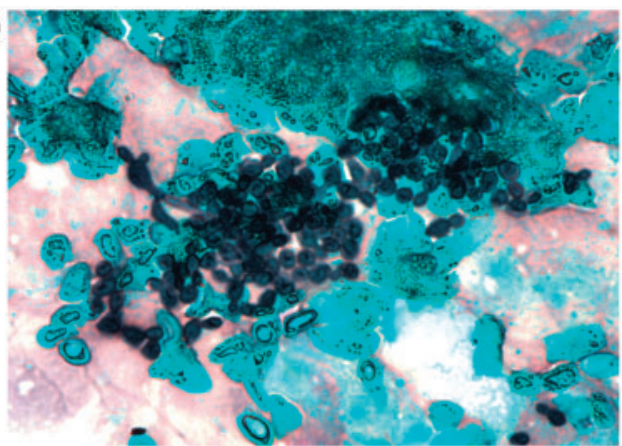

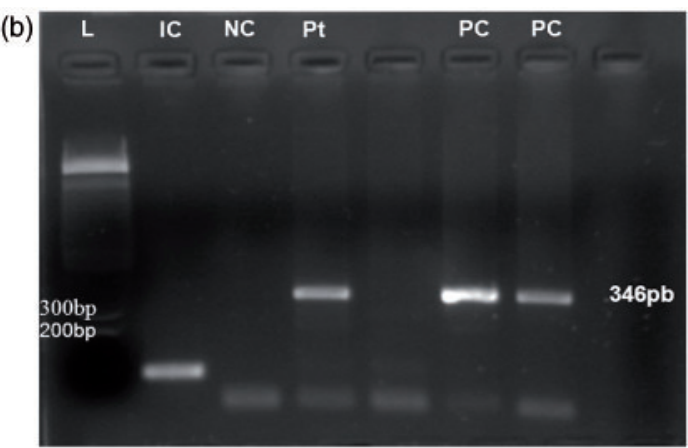

Fig. 2. (a) Bronchoscopic alveolar lavage specimen. Cluster of P. jirovecii cystic forms (centre). Grocott-Gomori methenamine silver stain (magnification $\times 40$ ). (b) Products of DNA amplification displayed on an ethidium gel, using the Pneumocystisspecific oligonucleotide primers (pAZ102E and pAZ102H) applied to DNA extracted from BAL fluid from the patient. Key: L, $1 \mathrm{~kb}$ molecular weight markers (sizes shown to the left of the column); IC, human $\beta$-globin as internal control; NC, negative control (with no added DNA template); Pt, patient; blank, one-fifth dilution of patient sample; PC, two P. jirovecii DNApositive controls. The Pneumocystis-specific amplification product $=346$ base pairs.

pAZ102H, designed to detect the gene encoding the mitochondrial large subunit ribosomal ribonucleic acid (LSU mt rRNA) gene of Pneumocystis spp. ${ }^{[5]}$ (Fig. 2b).

\section{Discussion}

The patient described here meets the diagnostic criteria for $\operatorname{VAP}^{[1]}$. The clinical and radiological progression while ventilated, the repeatedly negative results of bacterial culture of blood and endotracheal samples and demonstration of $P$. jirovecii in BAL fluid by histochemical staining and single round PCR strongly support the inference that Pneumocystis had a pathological role in this case. Cardiac and non-infectious pulmonary and extrapulmonary causes of ventilator-associated pulmonary infiltrates were excluded.

PCP as the cause of VAP in this patient probably represents progression from asymptomatic colonization to clinical disease in the context of a critically ill immunocompromised patient after cardiac surgery ${ }^{[6]}$. Cardiac surgery may induce immunosuppression; likely mechanisms include activation of anti-inflammatory cytokines, surgical trauma, reperfusion injury, and the effect of cardiopulmonary bypass ${ }^{[7,8]}$.

The origin of $P$. jirovecii in this patient is difficult to ascertain. Person-to-person transmission of $P$. jirovecii has been described in several inpatient and outpatient hospital clinical settings and person-to-person transmission has been suggested among immunocompetent contacts of patients 
with $\mathrm{PC}^{[9,10]}$. However, the slow growth rate of Pneumocystis makes it unlikely that this case represents a nosocomial infection acquired from another patient during her brief hospitalization $^{[11]}$. In addition, no other patients with PCP were contemporaneously diagnosed in the hospital. Asymptomatic infection with $P$. jirovecii is common in the general population and the role of these persons as an infective reservoir is possible ${ }^{[12,13]}$.

Pneumocystis jirovecii has previously been described as a cause of $\mathrm{VAP}^{[2,4,14]}$. Among 35 cases of VAP occurring in 2167 patients after cardiac surgery, fungi accounted for 15 episodes; of these two were due to $P$. jirovecii ${ }^{[2]}$. Puzio et al. ${ }^{[4]}$ described 27 patients from a cohort of 5026 who had undergone cardiac surgery and who developed prolonged respiratory failure requiring mechanical ventilation in whom atypical or opportunistic pathogens were identified. $P$. jirovecii was identified in $17 / 27$ patients (together with $C$. pneumoniae in three patients (one of whom also had $M$. pneumonia)). Another study described VAP caused by P. jirovecii in five elderly patients (age 7193 years $)^{[14]}$. Although our patient shares a history of cardiac surgery with these studies, by contrast our patient had no underlying medical condition, and was not taking corticosteroids or other immune suppressive drugs. In the study by Puzio et al. ${ }^{[4]}$, the significance of identifying $P$. jirovecii in tracheal aspirates is uncertain, as $7 / 27$ patients had a normal chest radiograph, 10 had underlying chronic lung disease and 4 were immunosuppressed because they had undergone heart or lung transplantation. All five elderly patients described by $\mathrm{Yu}$ and $\mathrm{Sun}^{[14]}$ had cancer or were receiving corticosteroid therapy.

$P$. jirovecii as a cause of VAP is extremely rare, and thus it should be considered in cases with highly suggestive thoracic CT imaging and/or negative bacterial cultures of BAL fluid.

\section{Teaching points}

- This case highlights the emerging importance of unusual pathogens, including P. jirovecii, in the pathogenesis of VAP in non-neutropenic, non-lymphopenic critically unwell, HIVuninfected patients undergoing cardiac surgery.

- Clinicians should be alert to the potential for atypical and opportunistic organisms to cause VAP in the postoperative period, especially among patients with prolonged respiratory compromise and a need for mechanical ventilation.

\section{Acknowledgements}

This work was supported in part by the Chilean Fund for Science and Technology (Fondecyt) grants 11100246 (ET) and 1100225 (SLV).

\section{References}

1. Valencia M, Torres A. Ventilator-associated pneumonia. Curr Opin Crit Care 2009; 15: 30-35. PMid:19186407.

2. Serban RI, Dan M, Pânzaru CV, et al. Etiology of ventilator-associated pneumonia at the cardiovascular surgery clinic of Iași. Rev Med Chir Soc Med Nat Iași 2012; 116: 15-21.

3. Serban RI, Dan M, Pânzaru CV, et al. Fungi as emergent etiologic agents in ventilatorassociated pneumonia after cardiac surgery. Rev Med Chir Soc Med Nat Iaşi 2010; 114: 1077-1082.

4. Puzio J, Kucewicz E, Siola M, et al. Atypical and opportunistic pulmonary infections after cardiac surgery. Anestezjol Intens Ter 2009; 41: 41-45. PMid:19517677.

5. Wakefield AE, Miller RF, Guiver LA, Hopkin JM. Oropharyngeal samples for detection of Pneumocystis carinii by DNA amplification. Q J Med 1993; 86: 401-406. PMid:8171187.

6. Monneret G, Venet F, Kullberg BJ, Netea MG. ICU-acquired immunosuppression and the risk for secondary fungal infections. Med Mycol 2011; 49(Suppl 1): S17-23. PMid:20718607.

7. Yeh $\mathrm{CH}$, Cheng $\mathrm{BC}$, Hsu CC, et al. Induced interleukin-19 contributes to cell-mediated immunosuppression in patients undergoing coronary artery bypass grafting with cardiopulmonary bypass. Ann Thorac Surg 2011; 92: 1252-1259. PMid:21855850.

8. Franke A, Lante W, Kackeldey V, et al. Pro-inflammatory cytokines after different kinds of cardio-thoracic surgical procedures: is what we see what we know?. Eur J Cardiothoracic Surg 2005; 28: 569-575. 
9. Schmoldt S, Schuhegger R, Wendler T, et al. Molecular evidence of nosocomial Pneumocystis jirovecii transmission among 16 patients after kidney transplantation. J Clin Microbiol 2008; 46: 966-971. PMid:18216217.

10. Gianella S, Haeberli L, Joos B, et al. Molecular evidence of interhuman transmission in an outbreak of Pneumocystis jirovecii pneumonia among renal transplant patients. Transpl Infect Dis 2010; 12: 1-10. PMid:19744285.

11. Aliouat el-M, Dujardin L, Marinez A, Duriez T, Ricard I, Dei-Cas E. Pneumocystis carinii growth kinetics in culture systems and in hosts: involvement of each life cycle parasite stage. J Eukaryot Microbiol 1999; 46: 116S-117S.

12. Medrano FJ, Montes-Cano M, Conde M, et al. Pneumocystis jirovecii in the general population. Emerg Infect Dis 2005; 11: 245-250. PMid:15752442.

13. Ponce CA, Gallo M, Bustamante R, Vargas SL. Pneumocystis colonization is highly prevalent in the autopsied lungs of the general population. Clin Infect Dis 2010; 50: 347-353. PMid:20047487.

14. Yu SY, Sun BJ. Ventilator-associated pneumonia caused by Pneumocystis carinii in the nonhuman immunodeficiency virus infection: a report of 5 cases. Zhonghua Nei Ke Za Zhi 2004; 43: 654-656. PMid:15500775. 